\title{
Constantin Fasolt
}

\section{Europäische Geschichte, zweiter Akt: Die Reformation"}

Der Überlieferung zufolge ist die Reformation ein Ereignis, das, erzwungen durch den Verfall der spätmittelalterlichen Kirche, ausgelöst von Martin Luther und getrieben durch ein neues Verständnis der christlichen Religion, die Einheit der mittelalterlichen Kirche für immer zerbrach, ihr Vertrauen auf gute Werke und Gesetze durch den Glauben und die Bibel ersetzte, ihren vielfältigen Mißbräuchen ein Ende machte, ihre Herrschaftsansprüche über den Staat in die verdienten Schranken wies, dem Individuum seine Freiheit gab und so einen Einschnitt in der Weltgeschichte hinterließ, der an Bedeutung nur dem Ende der Antike gleichgesetzt werden kann ${ }^{1}$. Reformatio ist ein alter Begriff, und Reformatio-

* Dieser Aufsatz ist eine leicht veränderte Fassung des Vortrags, den ich in München gehalten habe. Thomas A. Brady, Jr., möchte ich sehr herzlich für seine Einladung zum Forschungskolloquium danken und den Teilnehmern für die lebhafte Diskussion. Zu den hier angesprochenen Themen gibt es mehr gute wissenschaftliche Literatur in ganz verschiedenen Wissensgebieten und Sprachen als ein Einzelner je beherrschen könnte. Die Fußnoten verweisen deshalb nur auf mir bekannte Werke, die sich durch ihre besondere Nähe zu den hier aufgestellten Thesen, ihre historische Bedeutung, ihre begriffliche Klarheit, oder ihren Reichtum an weiterführenden Informationen auszeichnen. Sie machen keinen Anspruch auf Vollständigkeit, Objektivität oder Aktualität. Geübte Leser bitte ich um Verzeihung für die Lakunen und Ungleichmäßigkeiten, die ihnen zweifellos auffallen werden.

1 Klassisch formuliert bei Georg Wilhelm Friedrich Hegel, Vorlesungen über die Philosophie der Geschichte (Werke 12, hrsg. v. Eva Moldenhauer, Karl Markus Michel, Frankfurt a. M. 1970) 492: „Die Reformation ist aus dem Verderben der Kirche hervorgegangen. Das Verderben der Kirche ist nicht zufällig, nicht nur Mißbrauch der Gewalt und Herrschaft. Mißbrauch ist die sehr gewöhnliche Weise, ein Verderben zu benennen; es wird vorausgesetzt, daß die Grundlage gut, die Sache selbst mangellos, aber die Leidenschaften, subjektiven Interessen, überhaupt der zufällige Wille der Menschen jenes Gute als ein Mittel für sich gebraucht habe und daß es um nichts zu tun sei, als diese Zufälligkeiten zu entfernen. In solcher Vorstellung wird die Sache gerettet und das Übel als ein ihr nur Äußerliches genommen. Aber wenn eine Sache auf eine zufällige Weise mißbraucht wird, so ist dies nur im einzelnen, aber etwas ganz anderes ist ein allgemeines großes Übel in einer so großen und allgemeinen Sache, als eine Kirche ist. - Das Verderben der Kirche hat sich aus ihr selbst entwickelt; es hat eben sein Prinzip darin, daß das Dieses als ein Sinnliches in ihr, daß das Äußerliche, als ein solches, innerhalb ihrer selbst sich befindet.... Von jetzt an tritt sie binter den Weltgeist zurïck." (Hervorhebung im Original). Hegel faßt zusammen, S. 497: „Dies ist der wesentliche Inhalt der Reformation; der Mensch ist durch sich selbst bestimmt, frei zu sein.“ 
nen gab es im Mittelalter wie Sand am Meer ${ }^{2}$. Aber die Reformation war einzigartig, denn sie beendete das Mittelalter und läutete die Neuzeit ein.

Diese Kurzbeschreibung der Reformation genügt, um die beiden Grundmerkmale herauszustellen, denen die Reformation in der hergebrachten Geschichtsvorstellung ihre Einzigartigkeit verdankt. Das sind erstens der Bruch mit dem Katholizismus und zweitens der Bruch mit dem Mittelalter. Worin dieser Doppelbruch genau bestehen soll, braucht uns zunächst nicht aufzuhalten. Es genügt, ganz einfach festzuhalten, daß die traditionelle Sicht der Reformation eine grundlegende theologische Unterscheidung zwischen Katholiken und Protestanten und eine ebenso grundlegende Einteilung der Geschichte in Mittelalter und Neuzeit voraussetzt. Und zwar nicht empirisch, sondern analytisch. Sollte es sich nämlich herausstellen, daß der Gegensatz zwischen Protestanten und Katholiken fragwürdig ist und die Einteilung der Geschichte in Mittelalter und Neuzeit unhaltbar, dann wird der Begriff der Reformation (so als gäbe es nur eine, die den Namen in diesem emphatischen Sinne verdient) ebenso fragwürdig und unhaltbar. Bleiben wird dann von der Reformation nur noch eine Reformation - eine Reformation, die sich natürlich ebenso viel historische Individualität bewahren wird, wie jedes andere historische Ereignis auch, die sich aber von der langen Reihe aller anderen Ereignisse nicht mehr durch ihre einzigartige Stellung am Ende des universalen Katholizismus und am Beginn der Neuzeit unterscheiden wird.

Ich bin mir nicht ganz sicher, wem wir diese Legierung von theologischer Feindseligkeit mit historischer Dogmatik im Begriff der Reformation verdanken. Ich bin gerne bereit, Ranke zum hauptverantwortlichen Metallurgen zu erklären, so lange Hegel nicht vergessen wird ${ }^{3}$. Sicher bin ich mir aber, daß sie seit langem ein geradezu allergisches Unbehagen in historischen Köpfen erregt, vergleichbar dem neuralgischen Schmerz, den die zahnärztliche Verbindung von Goldplomben mit Silberamalgam erzeugen kann. Seit dem 19. Jahrhundert haben eine Reihe von so namhaften Beobachtern der europäischen Gesellschaft wie Karl Marx und Friedrich Engels, Max Weber und Ernst Troeltsch, Marc Bloch und Lucien Febvre und Norbert Elias diesem Unbehagen auf je verschiedene Weise zähneknirschend Ausdruck gegeben ${ }^{4}$. Und in den vergangenen fünfzig Jahren hat es sich in den

2 Zum Begriff der Reformation im Mittelalter Gerbart B. Ladner, The Idea of Reform: Its Impact on Christian Thought and Action in the Age of the Fathers (Cambridge, Mass. 1959); Karl F. Morrison, The Mimetic Tradition of Reform in the West (Princeton 1982); Giles Constable, The Reformation of the Twelfth Century (New York 1996); Karl Augustin Frech, Reform an Haupt und Gliedern: Untersuchung zur Entwicklung und Verwendung der Formulierung im Hoch- und Spätmittelalter (Europäische Hochschulschriften, Reihe III, Geschichte und ihre Hilfswissenschaften 510, Frankfurt, New York 1992); Phillip H. Stump, The Reforms of the Council of Constance (1414-1418) (Studies in the History of Christian Thought 53, hrsg. v. Heiko A. Oberman, Leiden, New York, Köln 1994).

${ }^{3}$ Leopold von Ranke, Deutsche Geschichte im Zeitalter der Reformation, 6 Bde. (GesamtAusgabe der Deutschen Akademie, Reihe 1, Werk 7, hrsg. v. Paul Fritz Joachimsen, München 1925). Vgl. Konrad Burdach, Reformation, Renaissance, Humanismus: Zwei Abhandlungen über die Grundlage moderner Bildung und Sprachkunst (Darmstadt 1974).

${ }^{4}$ Friedrich Engels, Der deutsche Bauernkrieg (Bücherei des Marxismus-Leninismus, Berlin 
innersten Hallen der historischen Gilde eine Stimme verschafft, die ebenso laut in geistes- wie in gesellschaftswissenschaftlichen Tönen und ebenso ausführlich auf Protestantisch wie auf Katholisch von der Unhaltbarkeit einer theologisch periodisierten Geschichte zu sprechen versteht ${ }^{5}$. Man sollte meinen, die alte Legie-

161989); Max Weber, Die protestantische Ethik und der "Geist“ des Kapitalismus, hrsg. v. Klaus Lichtblau, Johannes Weiss (Neue wissenschaftliche Bibliothek, Weinheim ${ }^{21996) ; ~ E r n s t ~}$ Troeltsch, Die Bedeutung des Protestantismus für die Entstehung der modernen Welt (Historische Bibliothek 24, München 1911); Marc Bloch, Les rois thaumaturges: Etude sur le caractère surnaturel attribué à la puissance royale, particulièrement en France et en Angleterre (Paris 21983); Lucien Febvre, Le Problème de l'incroyance au XVIe siècle: La Religion de Rabelais (Paris 1968); Norbert Elias, Über den Prozeß der Zivilisation: Soziogenetische und psychogenetische Untersuchungen, 2 Bde. (Basel 1939).

5 So hat Heiko Oberman, The Harvest of Medieval Theology: Gabriel Biel and Late Medieval Nominalism (Cambridge, Mass. 1963) erklärt, in welch hohem Maße der Geist der noch unlängst als dekadent verschrieenen nominalistischen Theologie als die reife Frucht bewundernswert tiefschürfender spätmittelalterlicher Geistesarbeit zu verstehen ist; vgl. Charles $E$. Trinkaus, Heiko A. Oberman (Hrsg.), The Pursuit of Holiness in Late Medieval and Renaissance Religion (Studies in Medieval and Reformation Thought 10, Leiden 1974). Paul Oskar Kristeller, Renaissance Thought and Its Sources, hrsg. v. Michael Mooney (New York 1979) hat die Wurzeln des Humanismus bis tief ins Mittelalter verfolgt und ihre symbiotische Verschlingung mit den verschiedensten Formen der Scholastik nachgewiesen. Brian Tierney, Religion, Law, and the Growth of Constitutional Thought, 1150-1650 (The Wiles Lectures given at the Queen's University of Belfast, Cambridge 1982); Francis Oakley, Natural Law, Conciliarism, and Consent in the Late Middle Ages: Studies in Ecclesiastical and Intellectual History (Variorum reprints CS189, London 1984) und Francis Oakley, Politics and Eternity: Studies in the History of Medieval and Early-Modern Political Thought (Studies in the History of Christian Thought 92, Leiden, Boston 1999) haben in der Nachfolge der klassischen Arbeit von John Neville Figgis, Studies of Political Thought from Gerson to Grotius, 14141625 (Cambridge 21916) den ununterbrochenen Fortschritt eines kirchlich begründeten Konstitutionalismus vom Mittelalter in die Neuzeit auf der "Straße von Konstanz bis $1688^{\text {“ }}$ erhellt. Geoffrey Barraclough, Papal Provisions: Aspects of Church History, Constitutional, Legal, and Administrative in the Later Middle Ages (Oxford 1935) und William Pantin, The English Church in the Fourteenth Century (Cambridge 1955) haben in aller Gründlichkeit nachgewiesen, wie oberflächlich die Verurteilung der sogenannten Mißbräuche der katholischen Kirche im Mittelalter ist. Bernd Moeller, Imperial Cities and the Reformation, übers. v. H. C. Erik Midelfort, Mark U. Edwards, Jr. (Philadelphia 1972), Peter Blickle, Gemeindereformation: Die Menschen des 16. Jahrhunderts auf dem Weg zum Heil (München 1985) und Thomas A. Brady, Jr., Turning Swiss: Cities and Empire, 1450-1550 (Cambridge 1985) haben mit bewundernswerter Klarheit demonstriert, wie eng die Reformation mit gesellschaftsgeschichtlichen Veränderungen in den Städten wie auch auf dem Lande verbunden war. Hubert Jedin, Geschichte des Konzils von Trient, 4 Bde. (Freiburg 1949-1975) hat dem Schattengewächs der Gegenreformation sein Wasser abgegraben. Ernst Walter Zeeden, Konfessionsbildung: Studien zur Reformation, Gegenreformation und katholischen Reform (Stuttgart 1985), Wolfgang Reinhard, Gegenreformation als Modernisierung? Prolegomena zu einer Theorie des konfessionellen Zeitalters, in: Archiv für Reformationsgeschichte 68 (1977) 22652, Heinz Schilling, Die Konfessionalisierung im Reich: Religiöser und gesellschaftlicher Wandel in Deutschland zwischen 1555 und 1620, in: Historische Zeitschrift 246 (1988) 1-45 und Ronnie Po-Chia Hsia, Social Discipline in the Reformation: Central Europe 1550-1750 (London 1989) haben einen Begriff der Konfessionalisierung entwickelt, in dem der theologische Gegensatz zwischen Katholiken und Protestanten weit an Bedeutung hinter religions- 
rung von Theologie und Periodisierung müsse längst zu einer neuen Sicht auf die Vergangenheit verschmolzen worden sein ${ }^{6}$.

Aber dem ist nicht so. Allen Bemühungen zum Trotz behauptet die Reformation ihre Einzigartigkeit noch immer mit geradezu furchteinflößender Langlebigkeit, wie ein blutsaugender Vampir am Nacken der Historiker, der sich auch von den heiligsten historischen Sakramenten nicht beschwören läßt. Warum? Woher diese unheimliche Langlebigkeit? Woher die verteufelte Kraft dieses Begriffes, die Waffen der kritischen Geschichtsschreibung so mühelos abprallen zu lassen?

Um auf diese Frage eine plausible Antwort geben zu können, möchte ich meine Leser bitten, mir für eine Weile in das sogenannte Mittelalter zu folgen. Denn in eben dem Maße, in dem die Grenze zwischen Mittelalter und Neuzeit verblichen ist, hat sich im Herzen des Mittelalters eine neue Grenze gebildet, deren Bedeutung für unser Verständnis der europäischen Geschichte noch längst nicht die Aufmerksamkeit erhalten hat, die sie verdient ${ }^{7}$. Sie liegt etwa zwischen dem Verfall des karolingischen Imperiums und der Neugründung, um nicht zu sagen, Reformation des Kaisertums in Deutschland und des Papsttums in Rom ${ }^{8}$. Der Streit

soziologisch begründeten Gemeinsamkeiten zurücksteht. Und so weiter. Schon Johannes Haller hatte so große Schwierigkeiten, seine Funde im gerade erst geöffneten Vatikanischen Archiv mit der Vorstellung vom Verfall der spätmittelalterlichen Kirche zu verbinden, daß es ihm nie gelang, sein großes Buch über Papsttum und Kirchenreform: Vier Kapitel zur Geschichte des ausgehenden Mittelalters (Berlin 1903) bis zur Reformation fortzuführen.

${ }^{6}$ An den verschiedensten Versuchen besteht kein Mangel, angefangen bei Gesamtdarstellungen der frühen Neuzeit wie bei Erich Hassinger, Das Werden des neuzeitlichen Europa, 1300-1600 (Braunschweig 1959) und Thomas A. Brady, Jr., Heiko A. Oberman, James D. Tracy (Hrsg.) Handbook of European History, 1400-1600: Late Middle Ages, Renaissance and Reformation, 2 Bde. (Leiden, New York, Köln 1994-95), über Zugriffe auf die Geschichte ganz Alteuropas bei Carlo M. Cipolla, Before the Industrial Revolution: European Society and Economy, 1000-1700 (New York 21980), Dietrich Gerhard, Old Europe: A Study of Continuity (New York 1981) und Heinz Scbilling, Die neue Zeit: Vom Christenheitseuropa bis zum Europa der Staaten. 1250 bis 1750 (Siedler Geschichte Europas, Berlin 1999), bis zu Teildarstellungen des historischen Lebens mit neuer Periodisierung bei Quentin Skinner, The Foundations of Modern Political Thought, 2 Bde. (Cambridge 1978), Steven Ozment, The Age of Reform, 1250-1550: An Intellectual and Religious History of Late Medieval and Reformation Europe (New Haven 1980) und Peter Blickle, Unruhen in der ständischen Gesellschaft, 1300-1800 (Enzyklopädie deutscher Geschichte 1, München 1988).

7 Richard W. Southern, The Making of the Middle Ages (New Haven 1953); Karl Leyser, Am Vorabend der ersten europäischen Revolution: Das 11. Jahrhundert als Umbruchszeit (Schriften des Historischen Kollegs, Dokumentationen 9, München 1994); R. I. Moore, The Formation of a Persecuting Society: Power and Deviance in Western Europe, 950-1250 (Oxford 1987); Harold J. Berman, Law and Revolution: The Formation of the Western Legal Tradition (Cambridge, Mass. 1983); Cinzio Violante, Johannes Fried (Hrsg.), Il Secolo XI: Una svolta? (Annali dell'Istituto storico italo-germanico 35, Bologna 1993). Im Hintergrund steht meist ungenannt Eugen Rosenstock-Huessy, Die Europäischen Revolutionen: Volkscharaktere und Staatenbildung (Jena 1931) und von demselben Autor Out of Revolution: Autobiography of Western Man (London 1938).

${ }^{8}$ Sie verringert also die Bedeutung, die den Karolingern bei der Gründung Europas von Christoper Daweson, The Making of Europe: An Introduction to the History of European Unity (London 1932) und Theodor Schieffer, Winfrid-Bonifatius und die christliche Grundlegung Europas (Freiburg 1954) zugeschrieben wurde. 
zwischen Kaiser und Papst um die Herrschaft über die Welt, der durch diese Doppelreformation ausgelöst wurde, ist traditionsgemäß eines der wichtigsten Themen der hochmittelalterlichen Geschichte ${ }^{9}$. Aber er ist nur eins von vielen verschiedenen Symptomen für einen Wandel, der sich auch auf ganz andere Gebiete des historischen Lebens erstreckte. In der Bevölkerungsgeschichte, zum Beispiel, vielleicht dem besten von allen Indizien für den Grundrhythmus der Geschichte, schwang damals das Pendel von der seit der Spätantike stetig anhaltenden Schrumpfung zu einem Wachstum um, das nicht einmal durch die Katastrophen des 14. und 17. Jahrhunderts aufzuhalten war und Europa einen proportional stetig zunehmenden Teil an der Weltbevölkerung gesichert hat, der erst in den Kriegen des 20. Jahrhunderts zurückging ${ }^{10}$. Parallel dazu änderte sich die Richtung der Bevölkerungsbewegungen von regelmäßigen Einwanderungen aus den Tiefen des eurasischen Kontinents und dem Mittelmeerraum in die europäische Halbinsel, die seit der Vorgeschichte zu belegen sind und sich im Frühmittelalter über Jahrhunderte hinweg in ungewöhnlicher Dichte folgten, zu der großen Auswanderung aus Europa, die in ihrer ersten Phase, der sogenannten inneren Kolonisation, Europa erstmals zu einem mehr oder weniger einheitlichen Kulturgebiet machte, und in einer zweiten Phase diese Kultur über den Rest der Welt verbreitet hat ${ }^{11}$. In der Wirtschaft fing dort der Handel zum ersten Mal seit der Spätantike wieder an,

"Percy Ernst Schramm, Kaiser, Rom und Renovatio: Studien zur Geschichte des römischen Erneuerungsgedankens vom Ende des karolingischen Reiches bis zum Investiturstreit, 2 Bde. (Studien der Bibliothek Warburg 17, Leipzig 1929); Augustin Fliche, La réforme Grégorienne, 3 Bde. (Spicilegium sacrum lovaniense, études et documents 6, 9, 16, Paris 19241937); Gerd Tellenbach, Libertas: Kirche und Weltordnung im Zeitalter des Investiturstreites (Forschungen zur Kirchen- und Geistesgeschichte 7, Stuttgart 1936); Uta-Renate Blumenthal, Der Investiturstreit (Urban Taschenbücher 335, Stuttgart 1982); Karl Leyser, Communications and Power in Medieval Europe, 2 Bde., hrsg. v. Timothy Renter (London, Rio Grande, Ohio 1992); Jean Rivière, Le problème de l'église et de l'état au temps de Philippe le Bel, Etudes et documents, fasc. 8 (Louvain 1926); Wilhelm Kölmel, Regimen Christianum: Weg und Ergebnisse des Gewaltenverhältnisses und des Gewaltenverständnisses (8. bis 14. Jahrhundert) (Berlin 1970); knapp aber ganz ausgezcichnet John A. Watt, Spiritual and Temporal Powers, in: J. H. Burns (Hrsg.), The Cambridge History of Medieval Political Thought, c. 350-c. 1450 (Cambridge 1988) 367-423.

10 Marcel Reinbard, André Armengaud, Jacques Dupaquier, Histoire générale de la population mondiale (Paris ${ }^{3} 1968$ ); Ernst Kirsten, Ernst Wolfgang Bucbbolz, Wolfgang Köllmann, Raum und Bevölkerung in der Weltgeschichte: Bevölkerungs-Ploetz, 4 Bde. (Würzburg 1965-1968).

11 Richard G. Klein, The Human Career: Human Biological and Cultural Origins (Chicago 1989); Robert J. Wenke, Patterns in Prehistory: Mankind's First Three Million Years (New York, Oxford ${ }^{3} 1990$ ); Herbert Schutz, The Prehistory of Germanic Europe (New Haven 1983); Norman J. G. Pounds, Hearth and Home: A History of Material Culture (Bloomington 1989); Lucien Musset, Les invasions, 2 Bde. (Nouvelle Clio: L'histoire et ses problèmes 12, Paris 1965); Robert Bartlett, The Making of Europe: Conquest, Colonization, and Cultural Change, 950-1350 (Princeton 1993); Janet L. Abu-Lughod, Before European Hegemony: The World System A.D. 1250-1350 (New York 1989); Pierre Chaunu, L'Expansion Européenne du XIIIe au XVe siècle (Nouvelle Clio: L'histoire et ses problèmes 26, Paris 1969); Wolfgang Reinhard, Geschichte der europäischen Expansion, 4 Bde. (Stuttgart 1983-1990); Eric $R$. Wolf, Europe and the People Without History (Berkeley 1982). 
sich auszubreiten, zunächst in Italien und an der Nordsee, dann zunehmend auf dem ganzen Kontinent ${ }^{12}$. In der Gesellschaft wurden die seit dem Altertum verschwundenen oder entvölkerten Städte nicht nur wieder entdeckt und neu belebt, sondern überhaupt zum ersten Mal in großem Maßstab auf mittel-, nord- und osteuropäischem Boden gegründet ${ }^{13}$. In der Kunstgeschichte verweist man gerne auf den Beginn der Gotik und die dramatische Verdrängung der Darstellung von Christus in seiner Majestät als König des Himmels und Richter des Weltalls durch das Bild des gekreuzigten Menschen und seiner schmerzensreichen Mutter Maria ${ }^{14}$. In der Theologie liegt dort die fundamentale Verschiebung der Bedeutung des verum corpus Christi von der Kirche als ganzer auf das Brot und den Wein der Eucharistie ${ }^{15}$. Im Kirchenrecht wurden die altertümlichen chronologischen Sammlungen konziliarer Dekrete und päpstlicher Briefe durch die systematischen Sammlungen ersetzt, die im 12. Jahrhundert in der Synthese Gratians gipfelten, die dann bis 1917 geltendes Recht blieb ${ }^{16}$. Im weltlichen Recht begann jenes Studium des römischen Rechts, von dem sämtliche Rechtssysteme des europäischen Kontinents bis heute abhängen ${ }^{17}$. Die Häresien, die neuen Orden (Clu-

12 Henri Pirenne, Medieval Cities: Their Origins and the Revival of Trade, übers. v. Frank D. Halsey (Princeton 1925); Robert S. Lopez, The Commercial Revolution of the Middle Ages, 950-1350 (Cambridge 1976).

13 Paul M. Hobenberg, Lynn Hollen Lees, The Making of Urban Europe, 1000-1950 (Harvard Studies in Urban History, hrsg. v. Stephan Thernstrom, Charles Tilly, Cambridge 1985); Fritz Rörig, Die curopäische Stadt und die Kultur des Bürgertums im Mittelalter, hrsg. v. Luise Rörig (Kleine Vandenhoeck Reihe 12-13, Göttingen 1955); Edith Ennen, Die europäische Stadt des Mittelalters (Sammlung Vandenhoeck, Göttingen +1987); Leonardo Benevolo, The European City (The Making of Europe, Oxford, Cambridge, Mass. 1993).

it Henri Focillon, Art d'Occident: Le moyen âge, roman et gothique (Paris 1938); Hugo Buchthal, Art of the Mediterranean World, A.D. 100 to 1400 (Art History Series 5, Washington, D. C. 1983); Erwin Panofsky, Gothic Architecture and Scholasticism (Wimmer lecture 1948, Latrobe 1951); James Clifton, The Body of Christ in the Art of Europe and New Spain, 1150-1800 (München, New York 1997); Klaus Schreiner, Maria: Jungfrau, Mutter, Herrscherin (München, Wien 1994).

15 Henri de Lubac, Corpus mysticum: L'eucharistic et l'Eglise au Moyen âge. Etude historique (Théologic 3, Paris 1944); Marie Dominique Chenu, La Théologie au douzième siècle (Etudes de philosophic médiévale 45, Paris 1957).

is Paul Fournier, Gabriel Le Bras, Histoire des collections canoniques en Occident depuis les Fausses Décrétales jusq'au Décret de Gratien, 2 Bde. (Bibliothèque d'histoire du droit, publiée sous les auspices de la Société d'histoire du droit, Paris 1931-1932); Stanley Chodoroz', Christian Political Theory and Church Politics in the Mid-Twelfth Century: The Ecclesiology of Gratian's Decretum (Berkeley 1972); Gabriel Le Bras, Charles Lefebore, Jacqueline Ramband, L'âge classique, 1140-1378: Sources et théorie du droit (Histoire du droit et des institutions de l'Eglise en occident 7, hrsg. v. Gabriel Le Bras, Paris 1965); Hans Erich Feine, Kirchliche Rechtsgeschichte: Die katholische Kirche (Köln ${ }^{5} 1972$ ).

17 Woldemar Engelmann, Die Wiedergeburt der Rechtskultur in Italien durch die wissenschaftliche Lehre (Leipzig 1938); Hermann Kantorowicz, Studies in the Glossators of the Roman Law: Newly Discovered Writings of the 12th Century, hrsg. v. William W. Buckland (Aalen 1969); Gaines Post, Studies in Medieval Legal Thought: Public Law and the State, 1100-1322 (Princeton 1964); Paul Koschaker, Europa und das Römische Recht (München 41966); Franz Wieacker, Privatrechtsgeschichte der Neuzeit: Unter besonderer Berücksichti- 
niazenser, Prämonstratenser, Zisterzienser, Franziskaner, Dominikaner), die Gilden, die Kreuzzüge, die Dreifelderwirtschaft, das Minnelied, die Primogenitur, die Universitäten - ich glaube, ich brauche keine weiteren Einzelheiten anzuhäufen, um die Gründe zu belegen, derentwegen eine respektable Zahl von Historikern die Wende vom Früh- zum Hochmittelalter so entscheidend für die europäische Geschichte hält, daß einer von ihnen soeben ein Buch mit dem Titel The First European Revolution darüber veröffentlicht hat ${ }^{18}$.

Diese Sichtweise verlegt das Kriterion für die Periodisierung der Geschichte auf die Entwicklung der europäischen Zivilisation als ganzer. Sie räumt den theologischen Erfindungen der frühen Neuzeit, der humanistischen Pflege des klassischen Latein und den Unterschieden zwischen den Nationen nur untergeordnete Bedeutung ein. Sie zerstört die traditionelle Dreiteilung der Geschichte in Altertum, Mittelalter und Neuzeit und verzichtet auf ihren Anspruch, für die gesamte Weltgeschichte zu gelten ${ }^{19}$. Das Frühmittelalter wird zum Bestandteil jenes langwierigen Zerfallsprozesses, in dem die auf den Mittelmeerraum konzentrierte Welt der hellenistisch-römischen Zivilisation in die bekannten drei Teile der griechischorthodoxen, arabisch-islamischen und lateinisch-germanischen Welten zerbrach $^{20}$. Das Hoch- und Spätmittelalter dagegen wird zur ersten Phase der Geschichte Europas, eben jener lateinisch-germanischen Welt, die nur im Vergleich mit der byzantinischen und der islamischen Welt (den beiden anderen Nachfolgern der Antike) verstanden werden kann, und deren zweite Phase bis zu jener industriellen Revolution reicht, die nicht nur die drei Nachfolger der Antike, sondern alle großen agrarischen Zivilisationen in der Welt von dem prominenten Platz verstieß, den sie seit der Entwicklung der Landwirtschaft in der Neusteinzeit behauptet hatten ${ }^{2 !}$.

gung der deutschen Entwicklung (Jurisprudenz in Einzeldarstellungen 7, Götringen 21967); Manlio Bellomo, L'Europa del diritto comune (Roma $\left.{ }^{5} 1991\right)$.

18 R. I. Moore, The First European Revolution (Oxford 2000).

19 Zu den Ursprüngen dieser Dreiteilung und ihren verschiedenen nationalen Ausprägungen Adalbert Klempt, Dic Säkularisierung der universalhistorischen Auffassung (Göttingen 1960); Roberto Weiss, The Renaissance Discovery of Classical Antiquity (Oxford 21988); Julian H. Franklin, Jean Bodin and the Sixteenth-Century Revolution in the Methodology of Law and History (New York 1963); J. G. A. Pocock, The Ancient Constitution and the Feudal Law: A Study of English Historical Thought in the Seventeenth Century (Cambridge 21987); Uwe Neddermeyer, Das Mittelalter in der deutschen Historiographic vom 15. bis zum 18. Jahrhundert: Geschichtsgliederung und Epochenverständnis in der frühen Neuzeit (Kölner historische Abhandlungen 34, hrsg. v. Erich Meutben, Köln, Wien 1988); Reinhart Koselleck, Vergangene Zukunft: Zur Semantik geschichtlicher Zciten (Frankfurt a. M. 1979). 20 Arnold H. M. Jones, The Later Roman Empire, 284-602: A Social, Economic, and Administrative Survey, 3 Bde. (Oxford 1964); Roger Collins, Early Medieval Europe, 300-1000 (History of Europe, New York 1991); Peter R. L. Brown, The Rise of Western Christendom: Triumph and Diversity, 200-1000 A.D. (The Making of Europe, Cambridge, Mass. 1995); Henri Pirenne, Mahomet et Charlemagne, hrsg. v. Jacques Pirenne (Paris 1937); Paul Egon Hübinger (Hrsg.), Zur Frage der Periodengrenze zwischen Altertum und Mittelalter (Weyc der Forschung 51, Darmstadt 1969); Richard Hodges, David Whitehouse, Mohammed, Charlemagne, and the Origins of Europe: Archacology and the Pirenne Thesis (Ithaca 1983). 2l So in welthistorischer Perspektive bei William H. McNeill, The Shape of European Hi- 
Die Grundzüge einer so verstandenen europäischen Geschichte lassen sich am einfachsten mit den Begriffen zeichnen, die vor allem Anthropologen gerne zur Analyse großer agrarischer Kulturen benutzen, und die Ernest Gellner brillant zusammengefaßt hat ${ }^{22}$ : auf der einen Seite der Großteil der Bevölkerung über das Land in relativ kleine Gruppen verteilt, die ihren Lebensunterhalt in der Landwirtschaft verdienen, politisch wenig zu sagen haben und relativ klar voneinander nicht so sehr durch geographische Entfernung und Transportschwierigkeiten als durch von Ort zu Ort verschiedene kulturelle Gewohnheiten, Sitten, Gebräuche, Dialekte und Sprachen separiert sind ${ }^{23}$. Auf der anderen Seite eine Elite, die zwar nur einen vergleichsweise kleinen Teil der Bevölkerung ausmacht, aber die Herrschaft über den Rest der Bevölkerung (abgesehen von sporadischen Unruhen, Skandalen, Krisen und Aufständen) fest in den Händen hält und überall mehr oder weniger dieselben Sitten hat, mehr oder weniger dieselbe Sprache spricht und daher in krassem Gegensatz zur Masse der Bevölkerung über eine Einheitlichkeit verfügt, die sich über den ganzen Kulturraum hinweg erstreckt. Dafür muß diese Elite allerdings entsprechend den wichtigsten Instrumenten der Machtausübung in zwei oder drei Gruppen unterteilt werden, die normalerweise in einem hierarchischen Unterordnungsverhältnis zueinander stehen, das sie ebenso scharf voneinander wie von der Masse der Bevölkerung trennt: eine mit Waffen ausgerüstete und kampfgeübte Aristokratie; eine schriftgebildete und aktenführende Klerisei; und oft auch ein handels- und geldkundiges Bürgertum ${ }^{2+}$. Auf der einen Seite also zahllose kleine Siedlungen, deren Einwohner zwar überall einem recht ähnlichen Leben nachgehen, sich aber schon nach ein paar Kilometern in der Fremde fühlen; und auf der anderen Seite Ritter, Mönche und Kaufleute, die zwar ganz verschiedene Lebenswege verfolgen, dafür aber von einem Ende Europas bis zum anderen miteinander in familiärer, geistiger und geschäftlicher Verbindung stehen und sich

story (New York 1974), J. M. Roberts, The Penguin History of the World (Harmondsworth 1990) und V. Gordon Childe, Man Makes Himself (London 1937). Dieselbe Periodisierung im Rückspiegel gesehen von Peter Laslett, The World We Have Lost Further Explored: England before the Industrial Age (New York ${ }^{31984)}$ und Jerome Blum, The End of the Old Order in Rural Europe (Princeton 1978). Vgl. Jerry H. Bentley, Patrick Manning, AHR Forum: Periodization in World History, in: American Historical Review 101 (1996) 749-82. 22 Ernest Gellner, Plough, Sword and Book: The Structure of Human History (Chicago 1988); vgl. Ernest Gellner, Nations and Nationalism (New Perspectives on the Past, hrsg. v. R. I. Moore, Ithaca 1983).

23 Besonders lebendig bei Emmanuel Le Roy Ladurie, Montaillou: Village occitan de 1294 à 1324 (Bibliothèque des histoires, Paris 1975) und besonders gründlich bei Emmanuel Le Roy Ladurie, Les paysans de Languedoc, 2 Bde. (Civilisations et société 42, Paris 1966).

24 Georges $D u b y$, Les trois ordres, ou: L'imaginaire du féodalisme (Bibliothèque des histoires, Paris 1978); Maurice Keen, Chivalry (New Haven 1984); Alexander Murray, Reason and Society in the Middle Ages (Oxford 1978); Michael T. Clanchy, From Memory to Written Record: England 1066-1307 (Oxford, Cambridge, Mass. ${ }^{2}$ 1993); Daniel Waley, The Italian City-Republics (London 1988); Heinz Schilling, Herman Diederiks (Hrsg.), Bürgerliche Eliten in den Niederlanden und in Nordwestdeutschland: Studien zur Sozialgeschichte des curopäischen Bürgertums im Mittelalter und in der Neuzcit (Städteforschung, Reihe A 23, Köln, Wien 1985). 
nicht nur überall besser miteinander verstehen, als mit der Masse der Bevölkerung, sondern auch überall ihre charakteristische Funktion in Krieg, Gottesdienst und Handel mehr oder weniger problemlos ausüben können.

Die Entwicklung Europas in dem so gesetzten Rahmen verdankte ihre Spannkraft in erster Linie der Masse der landsässigen Bevölkerung, die Europa buchstäblich kultivierte ${ }^{25}$. Aber die gesellschaftliche Form, in der sich diese Entwicklung ausprägte, wurde durch den Wettbewerb zwischen Adel, Klerisei und Bürgertum um Macht und Reichtum bestimmt ${ }^{26}$. Denn diese drei Wettbewerber schlossen eine Art stillschweigenden Gesellschaftsvertrag miteinander ab, der die Macht in drei deutlich voneinander getrennte Sphären aufteilte und jedem einzelnen von ihnen dadurch enorm vorteilhaft war, daß er ihnen sowohl das Recht wie die Freiheit gab, jeweils in ihrer eigenen Sphäre ihre Macht so aufzubauen, wie es ihnen billig erschien, und gleichzeitig die Grenzen zwischen ihnen absicherte. Die Unterpfänder, mit denen man sich gegenseitig des Friedens versicherte, waren der kirchliche Verzicht auf Nachwuchs, der adelige Verzicht auf die Güter der Kirche und der bürgerliche Verzicht auf Wucher. Zum Dank dafür erhielt der Adel kirchliche Unterstützung bei der Durchsetzung der Primogenitur und der nur dadurch möglichen Konzentration von Landbesitz in miteinander verschwägerten Adelsfamilien von europäischem Rang, erhielt die Kirche die Anerkennung ihrer symbolischen und rechtlichen Führung über ganz Europa, und erhielten die Kaufleute Markt- und Handelsfrieden. Die so gezogenen Grenzen wurden natürlich vielfach verletzt, und derartige Verletzungen stellen eines der beliebtesten Themen der Frühgeschichte Europas dar. Wie alle Skandale lenken sie aber von der Substanz der Geschichte ab. Denn die Substanz bestand aus einem ununterbrochenen Kampf von Adeligen mit Adeligen, von Geistlichen mit Geistlichen und von Bürgern mit Bürgern, verglichen mit dessen Intensität die Beziehungen zwischen den drei Gruppen wie der tiefste Frieden aussahen ${ }^{27}$.

Dieser Kampf ging durch drei große Phasen. Er begann mit dem enorm kreativen und enthusiastischen Ausbau neuer Institutionen im 11. und 12. Jahrhundert zu einer Zeit, als es für alle noch zahllose Möglichkeiten gab, ihr Glück zu ma-

25 Werner Rösener, The Peasantry of Europe: From the Sixth Century to the Present (The Making of Europe, Oxford, Cambridge, Mass. 1994); Marc Bloch, Les caractères originaux de l'histoire rurale française, 2 Bde. (Economies, sociétés, civilisations, Paris ${ }^{21952-1956) ; ~}$ B. H. Slicher van Bath, The Agrarian History of Western Europe, A.D. 500-1850, übers. v. Olive Ordish (London 1963).

26 Norbert Elias, Über den Prozess der Zivilisation: Soziogenetische und psychogenetische Untersuchungen, 2 Bde. (Basel 1939) ist aufschlußreich zum Wettbewerb im Adel, unterschlägt aber den geistlichen (zwischen Welt- und Ordensklerus) und den städtischen (zwischen Patriziern und Zünften).

27 Wie Joseph R. Strayer, The Reign of Philip the Fair (Princeton 1980) besonders überzeugend für die Beziehung zwischen dem König von Frankreich und dem Papsttum entgegen der geläufigen Meinung nachweist; vgl. im selben Sinne Justus Hashagen, Staat und Kirche vor der Reformation: Eine Untersuchung der vorreformatorischen Bedeutung der Laieneinflüsse in der Kirche (Essen 1931). 
chen, ohne ihren Mitbewerbern gleich ins Gehege zu kommen ${ }^{28}$. Er geriet im 13. und vor allem im 14. Jahrhundert in eine sehr bittere Phase, in der man sich innerhalb zunehmend eng erscheinender Grenzen gegenseitig das Überleben schwer machte ${ }^{29}$. Und er endete im 15. und 16. Jahrhundert mit der Bildung von Machtmonopolen, die zum ersten $\mathrm{Mal}$ in der Lage waren, sich ständig und unbestritten über alle Mitbewerber zu erheben. Die großen italienischen Familien wie die Este in Modena und Ferrara, die Visconti und Sforza in Mailand und die Medici in Florenz, die nach den spätmittelalterlichen Städtekämpfen die Regierung über ihre Mitbürger und Nachbarstädte in die Hand nahmen ${ }^{30}$; die Könige von England und Frankreich, die nach der großen Krise des Hundertjährigen Krieges ihre Macht über den Rest ihrer adeligen Genossen durchzusetzen wußten ${ }^{31}$; und nicht zuletzt der Papst, der nach der ebenso großen Krise des Schismas und der konziliaren Bewegung seine Macht über die Bischöfe und Orden bestätigte, ihr auf dem Konzil von Trient seine neuzeitliche Form gab und sich so zu einem souveränen Prinzen umwandelte, der schlechterdings nicht mit einem Gregor VII. oder einem Innozenz III. zu vergleichen ist und dessen Eigentümlichkeit Paolo Prodi so eindringlich beschrieben hat ${ }^{32}$; sie alle belegen das große Thema des späteren Mittelalters: die Wendung vom ständischen Wettbewerb zum monarchischen Monopol.

28 Charles Homer Haskins, The Renaissance of the Twelfth Century (Cambridge, Mass. 1927); Robert L. Benson, Giles Constable (Hrsg.), Renaissance and Renewal in the Twelfth Century (Cambridge, Mass. 1982); Brian Stock, The Implications of Literacy: Written Language and Models of Interpretation in the Eleventh and Twelfth Centuries (Princeton 1983); Colin Morris, The Discovery of the Individual, 1050-1200 (New York 1972); David C. Douglas, The Norman Fate, 1100-1154 (Berkeley 1976).

29 Christopher Allmand, The Hundred Years War: England and France at War, c. 1300 - c. 1450 (Cambridge Medieval Textbooks, Cambridge 1988); Etienne Delaruelle, E.-R. Labande Paul Ourliac, L'église au temps du grand schisme et de la crise conciliaire, 1378-1449 (Histoire de l'église 14, hrsg. v. Augustin Fliche, Paris 1962); Henri Pirenne, Les anciennes démocraties des Pays-Bas (Bibliothèque de philosophie scientifique, Paris 1910); Maude Violet Clarke, The Medieval City State: An Essay on Tyranny and Federation in the Later Middle Ages (London 1926); Gene Brucker, Florentine Politics and Society, 1343-1388 (Princeton Studies in History 12, Princeton 1962); Wilhelm Abel, Strukturen und Krisen der spätmittelalterlichen Wirtschaft (Quellen und Forschungen zur Agrargeschichte 32, Stuttgart 1980). 30 Ernst Salzer, Über die Anfänge der Signorie in Oberitalien: Ein Beitrag zur italienischen Verfassungsgeschichte (Historische Studien Heft 14, Berlin 1900); Daniel Meredith Bueno de Mesquita, Giangaleazzo Visconti, Duke of Milan (1351-1402): A Study in the Political Career of an Italian Despot (Cambridge 1941); Nicolai Rubinstein, The Government of Florence under the Medici (Oxford-Warburg Studies, Oxford 1966); Giorgio Chittolini, Anthony Molho, Pierangelo Schiera (Hrsg.), Origini dello Stato: Processi di formazione statale in Italia fra medioevo ed età moderna (Annali dell'Istituto Storico Italo-Germanico 39, Bologna 1994).

$31 \mathrm{~J}$. Russell Major, From Renaissance Monarchy to Absolute Monarchy: French Kings, Nobles, and Estates (Baltimore 1994); Davis Bitton, The French Nobility in Crisis, 1560-1640 (Stanford 1969); Geoffrey A. Elton, The Tudor Revolution in Government: Administrative Changes in the Reign of Henry VIII (Cambridge 1953); Lawrence Stone, The Crisis of the Aristocracy, 1558-1641 (New York, Oxford 1965).

32 Giuseppe Alberigo, Chiesa conciliare: Identità e significato del conciliarismo (Testi e ricerche di scienze religiose 19, Brescia 1981); Anthony Black, Monarchy and Community: Poli- 
Das Auftreten dieser Monopolisten erschütterte den politischen Rahmen, in dem die historische Entwicklung Europas bisher stattgefunden hatte, in einem $\mathrm{Maße}$, wie es seit dem Zerfall des karolingischen Imperiums nicht geschehen war. Denn zum einen beendeten sie jeweils in ihrer eigenen Sphäre den Wettbewerb um die Macht, dem sie bisher ihre ganze Aufmerksamkeit hatten widmen müssen. So gewannen sie eine ganz neue Bewegungsfreiheit, die sich in der Diplomatie und Kriegführung der frühen Neuzeit deutlich abzeichnet ${ }^{33}$. Zum anderen hatten sie erheblich mehr miteinander gemein, als mit den ihnen nun untertanen Verlierern oder auch ihren ehemaligen Bundesgenossen aus anderen Schichten der Gesellschaft im Kampf um die gesellschaftliche Macht. So machten sie sich gemeinsam auf den Weg zur Souveränität und der damit verbundenen Kodifizierung des Strafrechts nach innen und des Völkerrechts nach außen ${ }^{34}$. Und zum dritten entrissen sie der Kirche die Führung über Europa.

So zerbrach das Bündnis, das Geistliche, Adelige und Bürgerliche im 10. und 11. Jahrhundert miteinander abgeschlossen hatten. Es wurde durch einen neuen und ebenso stillschweigenden Gesellschaftsvertrag ersetzt, in dem sich die Monopolisten darauf einigten, das Erbe der römischen Kirche unter sich aufzuteilen, sich gegenseitig bei der Ausübung ihrer Macht über ihre Untertanen - Bürgerliche, Adelige und Geistliche - zu unterstützen und dafür darauf zu verzichten, dem einen die Untertanen oder das Territorium des anderen streitig zu machen. Das verlangte eine große Renovation im ganzen europäischen Haus, vom Keller bis zum Dachstuhl, im Garten und im Hof. Der geistliche Verzicht auf Nachwuchs, der adelige auf die Güter der Kirche und der bürgerliche auf Wucher erübrigten sich alle gleichermaßen. Die Vorliebe für die universale Hierarchie, die der gesellschaftlichen Struktur Früheuropas so ausgezeichnet entsprochen hatte, mußte durch die Beschränkung auf jene territorialen Grenzen ersetzt werden, bis zu denen die neuartige Macht des ortsansässigen Monopolisten jeweils reichte. Das hierarchische Verhältnis zwischen Geistlichen, Adeligen und Bürgerlichen mußte so umgedacht werden, daß es mit der Machtausübung von Monopolisten vereinbar wurde. Wenn bisher die Gleichheit der Menschen in einer Form von

tical Ideas in the Later Conciliar Controversy, 1430-1450 (Cambridge 1970); Ludwig Buisson, Potestas und Caritas: Die päpstliche Gewalt im Spätmittelalter (Forschungen zur kirchlichen Rechtsgeschichte 2, Köln 21982); Paolo Prodi, Il sovrano pontefice: Un corpo e due anime; La monarchia papale nella prima età moderna (Bologna 1982).

${ }^{33}$ Richard Bonney, The European Dynastic States, 1494-1660 (Short Oxford History of the Modern World, hrsg. v. J. M. Roberts, Oxford 1991); Garrett Mattingly, Renaissance Diplomacy (Boston 1955); Geoffrey Parker, The Military Revolution: Military Innovation and the Rise of the West, 1500-1800 (The Lees Knowles lectures 1984, Cambridge 1988).

${ }^{34}$ Francis H. Hinsley, Sovereignty (Cambridge, New York 21986); Julian Franklin, Jean Bodin and the Rise of Absolutist Theory (Cambridge Studies in the History and Theory of Politics, Cambridge 1973); Jobn Langbein, Prosecuting Crime in the Renaissance: England, Germany, France (Studies in Legal History, Cambridge, Mass. 1974); Edward Peters, Torture (Philadelphia 21996); M. H. Keen, The Laws of War in the Late Middle Ages (Studies in Political History, London 1966); Ernst Reibstein, Völkerrecht: Eine Geschichte seiner Ideen in Lehre und Praxis, 2 Bde. (Orbis academicus: Problemgeschichten der Wissenschaft in Dokumenten und Darstellungen, Freiburg 1958-1963). 
Christlichkeit gefunden worden war, die in keinem Gegensatz zu einer Hierarchie zu stehen schien, die Leibeigene und Freie, Männer und Frauen, Herren und Vasallen, Geistliche und Weltliche einander auf die verschiedenste Art und Weise über- und unterordnete, so wurde dieselbe Gleichheit jetzt in einer Menschlichkeit gefunden, die in keinem Gegensatz zu den verschiedenen staatlichen und gesellschaftlichen Funktionen zu stehen schien, durch die sie sich nunmehr zunehmend im privaten, gesellschaftlichen und öffentlichen Leben voneinander differenzierten. Aus dem Christenmenschen wurde der Italiener, der Deutsche, der Franzose, der Engländer, der Spanier, aus dem Adeligen wurde der Soldat, aus dem Geistlichen der Bureaukrat, aus dem Bürger der Geschäftsmann, und aus allen wurde der Untertan. Der Gottesdienst wurde zum Dienst an der Natur, die Kirche zur Nation und die Hierarchie zur Arbeitsteilung.

Dieser Umschwung fand in ganz Europa statt. Er spiegelt sich in der europäischen Expansion nicht weniger als in den neuen wissenschaftlichen Entdeckungen; in der Beziehung zwischen den Geschlechtern ebenso wie in der Beziehung zwischen Herrschern und Beherrschten; in der veränderten Stellung der Juden und in der neuen Würde des Hausvaters; in der Kunst der Renaissance und in den Silberminen Sachsens. Die Erfindung der dreidimensionalen Perspektive in der Malerei ist ein besonders schönes Beispiel dafür, weil sie den Standpunkt des Betrachters so klar zu einem Monopol erhebt, dem sich alle im Gemälde dargestellten Dinge unterzuordnen haben ${ }^{35}$. Aber dieser Umschwung ereignete sich nicht auf einmal, sondern tausendmal, in vielen kleinen und großen Schritten, die die ganze frühe Neuzeit durchquerten und in verschiedenen Gebieten über ganz verschiedene Wege führten und jeweils mit ganz verschiedener Geschwindigkeit genommen wurden.

In Italien war die Machtausübung längst soweit in die Hände der merkantilen städtischen Eliten übergegangen, daß man kaum von einem italienischen Adel sprechen kann, ohne seine engen Beziehungen zum Bürgertum und seinen Wohnsitz in den italienischen Städten zu erwähnen. Dort hatten Adel und Bürgertum am frühesten geographisch verhältnismäßig kleine, aber institutionell bemerkenswert stabile Machtmonopole ausgebildet, sich am besten an die schriftlichen $\mathrm{Me}-$ thoden der Klerisei gewöhnt, und deshalb schon im 14. und 15. Jahrhundert die geistige Führung so weit von der Kirche übernommen, daß sie energisch in eigener Sprache und in eigenem Namen auftreten konnten ${ }^{36}$. Die enge biographische Verbindung zwischen Kanonisten und Humanisten im Dienste des Papstes (wie zum Beispiel bei Petrarca und Alberti) ist nur ein besonders reizendes Indiz dafür.

35 Dazu scharf beobachtend Paul Feyerabend, Progress in Philosophy, the Sciences and the Arts, in: Paul Feyerabend, Farewell to Reason (London, New York 1987) 143-161.

36 Lauro Martines, Power and Imagination: City-States in Renaissance Italy (New York 1979); Peter Burke, The Italian Renaissance: Culture and Society in Italy (Princeton 21986); Gene Brucker, The Civic World of Early Renaissance Florence (Princeton 1977); George Andrew Holmes, The Florentine Enlightenment, 1400-1500 (New York 1969); Giorgio Chittolini, Dietmar Willoweit (Hrsg.), Statuti, città, territori in Italia e Germania tra Medioevo ed età moderna (Annali dell'Istituto storico italo-germanico 30, Bologna 1991). 
In Frankreich dagegen hatte der Adel sich erheblich größere gesellschaftliche Selbständigkeit bewahrt. Denn dort sah er sich zwar mit einem Königtum konfrontiert, das nur zu gerne, von wenigen in ihrer langfristigen Bedeutung leicht überschätzten Skandalen abgesehen, bereit war, in engster Zusammenarbeit mit dem Papsttum, Adel und Bischöfe gleichermaßen zu unterwerfen, und sich damit auf lange Sicht gesehen auch viel größere Macht erwarb, als die italienischen Städte. Das dauerte aber länger. Das eindrucksvolle Experiment von Avignon scheiterte im Hundertjährigen Krieg, weil die universalen Ansprüche des Papsttums es damals so wenig wie heute erlaubten, jeder Nation ihren eigenen Papst zu geben. Der Adel wurde erst unter Ludwig XIV. endgültig gezähmt, und die französische Kirche erhielt sich im Gallikanismus bis zur französischen Revolution eine Unabhängigkeit, die ihr in Italien schon lange abhanden gekommen war ${ }^{37}$.

In England lief die Entwicklung ähnlich aber konzentrierter ab, weil England besonders früh eine solide Monarchie und eine Schriftkultur entwickelt hatte, die nicht nur alles weit in den Schatten stellte, was sonst nördlich der Alpen zu finden war, sondern sich auch von Anfang an in der Landessprache niederschlug 38 . Domesday Book ist einzigartig in der europäischen Geschichte. Und England war das einzige europäische Land, das sich einen professionellen Stand von Juristen schuf, der nicht an Universitäten ausgebildet wurde (sondern an den Inns of Court), sich nicht auf Latein verließ (sondern auf Anglo-Französisch) und nicht das römische Recht rezipierte (sondern sich auf Präzedenzfälle und Gewohnheitsrecht verließ) $)^{39}$. Nicht zuletzt deshalb ist England auch der einzige europäische Staat, der sich eine gut funktionierende Staatskirche schaffen und bis heute erhalten konnte ${ }^{40}$.

In Deutschland dagegen traf die Verschmelzung von Kirche und Adel auf erheblich größere Schwierigkeiten. In Deutschland war die Anerkennung des mo-

37 Joseph R. Strayer, The Reign of Philip the Fair (Princeton 1980); Guillaume Mollat, Les papes d'Avignon, 1305-1378 (Paris 101965); Victor Martin, Les origines du Gallicanisme, 2 Bde. (Paris 1939); David Potter, A History of France, 1460-1560: The Emergence of a Nation State (New York 1995); Roland E. Mousnier, Les institutions de la France sous la monarchie absolue: 1598-1789, 2 Bde. (Histoire des institutions, Paris 1974-1980).

38 Frederic William Maitland, The Constitutional History of England (Cambridge 1909); Jobn Edward Austin Jolliffe, Angevin Kingship (London 1955); Henry G. Richardson, George O. Sayles, The Governance of Mediaeval England from the Conquest to Magna Carta (Edinburgh University publications, History, Philosophy \& Economics 16, Edinburgh 1963); Maurice H. Keen, England in the Later Middle Ages: A Political History (London 1973).

39 Frederic William Maitland, Domesday Book and Beyond: Three Essays in the Early History of England (Cambridge 1897); Frederick Pollock, Frederic William Maitland, The History of English Law Before the Time of Edward I, 2 Bde. (Cambridge 21968); Jobn Hamilton Baker, An Introduction to English Legal History (London ${ }^{3} 1990$ ).

40 Zachary N. Brooke, The English Church and the Papacy: From the Conquest to the Reign of John (Cambridge 21989); Christopher Robert Cheney, From Becket to Langton: English Church Government, 1170-1213 (Ford lectures 1955, Manchester 1956); Marion Gibbs, Jane Lang, Bishops and Reform, 1215-1272, with Special Reference to the Lateran Council of 1215 (Oxford Historical Series, London 1934). 
nastisch verfaßten und von Rom geleiteten lateinischen Klerus, die das eigentliche Thema des Investiturstreits darstellt, auf so heftigen Widerstand gestoßen, daß der stillschweigende Vertrag zwischen Adeligen, Geistlichen und Bürgerlichen nur teilweise ausgeführt werden konnte. Konfrontiert mit der Feindseligkeit eines Kaisers, der im 11. Jahrhundert über die mächtigste staatliche Organisation in Europa verfügte, hatte Rom kaum eine andere Wahl gehabt, als seine Ansprüche an den deutschen Adel wenigstens zeitweilig zurückzuschrauben. In Italien hatte das Papsttum die Städte auf seiner Seite und in England und Frankreich das Königtum. Aber in Deutschland gab es kein Bürgertum, das sich dem italienischen hätte vergleichen können, und ein Königtum, das ihm so wohlgesonnen gewesen wäre, wie der allerchristlichste König von Frankreich, gab es schon gar nicht.

Das Ergebnis ist seit Aloys Schulte bekannt: Der deutsche Adel behauptete seine Unabhängigkeit von und seine Macht über die Kirche in einem Maße, das ihn im Laufe der Zeit als vergleichsweise ungebildet und die Kirche als vergleichsweise korrupt erscheinen ließ ${ }^{41}$. Deutschland bekam seine ersten Universitäten erst gegen Ende des 14. Jahrhunderts, zwei bis drei Jahrhunderte nach England, Frankreich und Italien ${ }^{42}$. Und deutsche Städte wuchsen erst im Laufe des 15. und 16. Jahrhunderts zu einer Größe, Macht und Anzahl heran, die ihnen das Selbstbewußtsein und die gebildete Masse gab, die in Italien schon seit langem zur Verfügung gestanden hatten ${ }^{43}$. In mancher Hinsicht mag es so erscheinen, als ob die Voraussetzungen, auf denen die Gregorianische Reformation der europäischen Kirche beruht hatte, in Deutschland erst im 15. Jahrhundert gegeben waren ${ }^{44}$. So

${ }^{41}$ Aloys Schulte, Der Adel und die deutsche Kirche im Mittelalter (Studien zur Sozialrechtsund Kirchengeschichte, Stuttgart 1910); vgl. John B. Freed, The Friars and German Society in the Thirteenth Century (Cambridge, Mass. 1977); Hellmuth Rössler (Hrsg.), Deutscher Adel, 1430-1555 (Schriften zur Problematik der deutschen Führungsschichten in der Neuzeit 1, Darmstadt 1965); Wolfgang Mommsen, Peter Alter, R. Scribner (Hrsg.), Stadtbürgertum und Adel in der Reformation: Studien zur Sozialgeschichte der Reformation in England und Deutschland (Veröffentlichungen des Deutschen Historischen Instituts London 5, Stuttgart 1979); F. R. H. Du Boulay, Germany in the Later Middle Ages (New York 1983); Joachim Leuschner, Deutschland im späten Mittelalter (Kleine Vandenhoeck-Reihe 1410, Göttingen 21983).

42 Hilde de Ridder-Symoens (Hrsg.), Universities in the Middle Ages (A History of the University in Europe 1; Cambridge 1992); Hilde de Ridder-Symoens (Hrsg.), Universities in Early Modern Europe (1500-1800) (A History of the University in Europe 2, Cambridge 1995); Hellmuth Rössler, Günther Franz (Hrsg.), Universität und Gelehrtenstand, 1400-1800 (Deutsche Führungsschichten in der Neuzeit 4, Limburg 1970); Günther Franz (Hrsg.), Beamtentum und Pfarrerstand, 1400-1800 (Deutsche Führungsschichten in der Neuzeit 5, Limburg a.d.L. 1972); Rainer Christof Scbwinges, Deutsche Universitätsbesucher im 14. und 15. Jahrhundert (Studien zur Sozialgeschichte des Alten Reiches, Wiesbaden 1986).

43 Jan de Vries, European Urbanization, 1500-1800 (Cambridge, Mass. 1984); Hans Planitz, Die deutsche Stadt im Mittelalter, von der Römerzeit bis zu den Zunftkämpfen (Graz 1954); Hartmut Boockmann, Die Stadt im späten Mittelalter (München 21987); Heinz Scbilling, Die Stadt in der frühen Neuzeit (Enzyklopädie deutscher Geschichte 24, München 1993); Hellmuth Rössler (Hrsg.), Deutsches Patriziat, 1430-1740 (Schriften zur Problematik der deutschen Führungsschichten der Neuzeit 3, Limburg a. d. L. 1968).

${ }^{44}$ Hagen Keller, Adelsherrschaft und städtische Gesellschaft in Oberitalien, 9.-12. Jahrhun- 
läßt es sich verstehen, warum das spätmittelalterliche Deutschland zunächst so besonders hartnäckig um die Reform der Kirche rang, die in der Zeit des großen Schismas nötig geworden war, und sich dabei so besonders hartnäckig auf die mittelalterliche Tradition der allgemeinen Konzile versteifte, die sich in Konstanz und in Basel zum ersten $\mathrm{Mal}$ auf deutschem Boden trafen ${ }^{45}$. So kommt es aber auch, daß gerade Deutschland kurz danach so besonders explosiv mit der römischen Kirche brach und sich für immer mit einer Spaltung in Konfessionen abfinden mußte, die sich weder einigen noch gegenseitig beherrschen konnten.

In diesem großen Wandel war die Kirche zweifellos der größte Verlierer. Die Kirche hatte dank ihrem römischen Erbe und dank dem Mönchtum seit langem die beste Vorstellung davon gehabt, was ein Monopol ist und wie man es so durchsetzt, daß der Wettbewerb aufhört ${ }^{46}$. Sie hatte bereits seit der Jahrtausendwende systematisch ein Monopol nicht nur beansprucht, sondern auch gegen ihren kaiserlichen Rivalen behauptet. Sie hatte sich im Papsttum, den Konzilen, den Legaten, den Orden, den Universitäten und dem kirchlichen Recht Institutionen mit buchstäblich europaweiter Gewalt geschaffen, die allem, was Adelige und Bürgerliche zu bieten gehabt hatten, weit voraus waren. Auf die darin angesammelte Macht nun verzichten zu müssen, traf die Kirche um genau soviel bitterer, als sie sich über den Wettbewerb zwischen Adeligen, Geistlichen und Bürgerlichen erhaben gedacht hatte. Das historische Symbol für die Bitterkeit dieser Niederlage ist die Kleinheit des vatikanischen Staates, die in so sinnvollem Gegensatz zu den universalen Ansprüchen seines Herrschers steht.

Dieser Verlust wird gerne als Säkularisation bezeichnet. Das führt aber in die Irre ${ }^{47}$. Denn wenn die Kirche auch der große Verlierer des frühneuzeitlichen Wan-

dert (Bibliothek des Deutschen Historischen Instituts in Rom 52, Tübingen 1980); Cinzio Violante, La società milanese nell'età precomunale (Biblioteca universale Laterza 11, Roma 1981); Gerhard Dilcher, Die Entstehung der lombardischen Stadtkommune: Eine rechtsgeschichtliche Untersuchung (Untersuchungen zur deutschen Staats- und Rechtsgeschichte, n. F. 7, Aalen 1967).

45 Joachim Stieber, Pope Eugenius IV, the Council of Basel, and the Secular and Ecclesiastical Authorities in the Empire (Studies in the History of Christian Thought 13, Leiden 1978); Hermann Heimpel, Die Vener von Gmünd und Strassburg, 1162-1447: Studien und Texte zur Geschichte einer Familie sowie des gelehrten Beamtentums in der Zeit der abendländischen Kirchenspaltung und der Konzilien von Pisa, Konstanz und Basel, 3 Bde. (Veröffentlichungen des Max-Planck-Instituts für Geschichte 52, Göttingen 1982); Heinz Angermeier, Die Reichsreform 1410-1555: Die Staatsproblematik in Deutschland zwischen Mittelalter und Gegenwart (München 1984); Convegno storico internazionale, Conciliarismo, stati nazionali, inizi dell'umanesimo: Atti del XXV Convegno storico internazionale, Todi, 9-12 ottobre 1988 (Atti dei convegni dell'Accademia tudertina e del Centro di studi sulla spiritualità medievale, nuova ser. 2, Spoleto 1990).

46 Walter Ullmann hat oft übertrieben, aber nicht immer mit Unrecht; s. Walter Ullmann, The Relevance of Medieval Ecclesiastical History: An Inaugural Lecture (Cambridge 1966); Walter Ullmann, The Growth of Papal Government in the Middle Ages: A Study in the Ideological Relation of Clerical to Lay Power (London ${ }^{3} 1970$ ); vgl. die Kritik von Francis Oakley, Celestial Hierarchies Revisited: Walter Ullmann's Vision of Medieval Politics, in: Past and Present 60 (1973) 3-48.

47 Damit hat Hans Blumenberg, Die Legitimität der Neuzeit (Suhrkamp Taschenbuch Wis- 
dels war, so doch nicht, weil die Methoden der Klerisei abgelehnt wurden, sondern ganz im Gegenteil, weil die Laien, die bei ihr so lange in die Schule gegangen waren, nun verlangten, diese Methoden in eigenem Namen und in eigener Sprache auszuüben. Das Monopol über die Schriftkultur, das die Kirche behauptet und auf dem ihre Macht beruht hatte, wurde in der Tat aufgelöst, aber nur, um von Laien in die Hand genommen und viel intensiver als bisher in die Tat umgesetzt zu werden, nicht mehr unter der Leitung des Papstes, sondern in höfischen und hauptstädtischen Kammern und Bureaus, und nicht mehr von zölibatären Priestern und Mönchen, sondern von Ministern, Gelehrten und Wissenschaftlern im Dienste des Staates. Die symbolische Macht der Kirche wurde ganz und gar nicht zerstört. Sie wurde auf die Nation übertragen. Die Nation ist die wahre Kirche der Moderne. Sie betet am Altar der Natur, empfängt ihr Sakrament von den Priestern der Wissenschaft und erhält Vergebung für vergangene Sünden von Historikern. Hobbes war der erste, der das klar sah, und Rousseau pflichtete ihm in dieser Hinsicht ausdrücklich bei, mit der spitzen Bemerkung, daß Hobbes seine Feinde gerade nicht seinen Irrtümern verdankte, sondern seinen wahren Erkenntnis$\operatorname{sen}^{48}$.

Diese Kontinuität in der Entwicklung der europäischen Gesellschaft, von der Kirche zur Nation, auf sozialer wie auch auf geistiger Ebene, von der Gründung Europas im 10. Jahrhundert bis zu seiner Selbstzerfleischung im 20., ist eine so grundlegende Tatsache, daß sich ohne ihre Anerkennung kein angemessenes Verständnis der Reformation finden lassen wird. Sie ist nicht als Säkularisation zu verstehen und kaum als Fortschritt, vielleicht am besten als Laizisierung; nicht als weltlicher Bruch mit geistlicher Herrschaft, oder protestantische Emanzipation

senschaft 24, 79, 174, Frankfurt a. M. 21973-1976) recht, wenn auch aus Gründen, die den hier genannten fast diametral entgegenstehen; vgl. Hermann Lübbe, Säkularisierung: Geschichte eines ideenpolitischen Begriffs (Freiburg 1965).

48 "The laws of God, therefore, are none but the laws of nature, whereof the principal is that we should not violate our faith, that is, a commandment to obey our civil sovereigns, which we constituted over us by mutual pact with one another.... So that the faith of Christians ever since our Saviour's time hath had for foundation, first, the reputation of their pastors, and afterward, the authority of those that made the Old and New Testament to be received for the rule of faith - which none could do but Christian sovereigns, who are therefore the supreme pastors, and the only persons whom Christians now hear speak from God - except such as God speaketh to, in these days, supernaturally." Thomas Hobbes, Leviathan, Kapitel 43, „Of what is Necessary for a Man's Reception into the Kingdom of Heaven, "Abschnitt 5, hrsg. v. Edwin Curley (Indianapolis 1994) 399-400. Vgl. Jean-Jacques Rousseau, Du contrat social, Buch 4, Kapitel 8, hrsg. v. Robert Derathé (Collection Folio essais 233, Paris 1964) 285: „De tous les Auteurs Chrétiens le philosophe Hobbes est le seul qui ait bien vû le mal et le remede, qui ait osé proposer de réunir les deux têtes de l'aigle, et de tout ramener à l'unité politique, sans laquelle jamais Etat ni Gouvernement ne sera bien constitué. Mais il a dû voir que l'esprit dominateur du Christianisme étoit incompatible avec son sistême, et que l'intérêt du Prêtre seroit toujours plus fort que celui de l'Etat. Ce n'est pas tant ce qu'il y a d'horrible et de faux dans sa politique que ce qu'il y a de juste et de vrai qui l'a rendue odieuse." Vgl. Constantin Fasolt, Sovereignty and Heresy, in: Max Reinhart (Hrsg.), Infinite Boundaries: Order, Disorder, and Reorder in Early Modern German Culture (Sixteenth Century Essays \& Studies 40, Kirksville, Missouri 1998) 381-391. 
von katholischer Unterdrückung, sondern als Fortpflanzung geistlicher Herrschaft in weltlichen Händen ${ }^{49}$. Sie übergreift die örtlichen, zeitlichen und gedanklichen Unterschiede zwischen den Nationen (Deutschland, Italien, Spanien, Frankreich, England, ...) und zwischen den Konfessionen (Katholiken, Protestanten, Anglikaner, Gallikaner, Puritaner, Jansenisten, ...), ganz ohne dieselben auszulöschen ${ }^{50}$. Sie bildet den stillen, bleibenden, zumeist unbewußten, abgelehnten und von konfessionell oder national gestimmten Historikern in seiner Realität oft schlechthin geleugneten gemeinsamen europäischen Hintergrund, vor dem sich die Reformation nicht weniger als die anderen großen Ereignisse der europäischen Geschichte abspielte.

So verliert die Reformation ihre Einzigartigkeit. Sie bedeutet keinen Bruch mit der vorausgegangen Entwicklung Europas, sondern ganz im Gegenteil ihre Fortsetzung und Intensivierung. Sie war eben „Europäische Geschichte, Zweiter Akt“. Kein Neubeginn, sondern ein Szenenwechsel. Neue Umstände, aber immer noch dasselbe Drama mit denselben Darstellern. Eine neue Theologie, aber im Dienste eines Zieles, das schon seit dem 11. Jahrhundert festlag ${ }^{51}$. Die Reformation ist auch nicht deutsch. Sie ist nur der bewußte deutsche Ausdruck für einen unbewußten gesellschaftlichen Wandel, der in ganz Europa stattfand und sich ebenso deutlich in Renaissance und Humanismus abzeichnet, unterschieden nur durch die verschiedenen Voraussetzungen, unter denen derselbe Wandel in verschiedenen Gebieten Europas stattfand, je nachdem, wie erfolgreich die Kirche darin gewesen war, sich mit ihren Führungsansprüchen durchzusetzen, welche Kompromisse sie hatte schließen müssen und wie weitgehend die Laieneliten es bereits verstanden hatten, die Führung von ihr zu übernehmen ${ }^{52}$. Die nationalen Unterschiede zwischen Deutschland, England, Frankreich und Italien sind keine

49 Joseph R. Strayer, The Laicization of French and English Society in the Thirteenth Century, in: Speculum 15 (1940) 76-86; Georges de Lagarde, La naissance de l'esprit laïque au déclin du Moyen Age, 6 Bde. (Paris 21942-1948); Michael Stolleis, ,Konfessionalisierung' oder ,Säkularisierung' bei der Entstehung des frühmodernen Staates, in: Ius commune: Zeitschrift für Europäische Rechtsgeschichte 20 (1993) 1-23.

50 Max Weber, Die protestantische Ethik und der Geist des Kapitalismus, in: Max Weber, Gesammelte Aufsätze zur Religionssoziologie (Tübingen 21922-1923) 1:1-206, war mit dem Begriff der innerweltlichen Askese sicher auf dem richtigen Weg, nur eben nicht darin, ihn auf den Protestantismus zu beschränken, wie Hugh R. Trevor-Roper, Religion, the Reformation and Social Change, in: Hugh R. Trevor-Roper, The European Witch-Craze of the Sixteenth and Seventeenth Centuries and Other Essays (New York 1969) 1-45, scharf pointiert hat; vgl. Kurt Samuelsson, Religion and Economic Action: A Critique of Max Weber, hrsg. v. D. C. Coleman, übers. v. E. G. French (New York 1964); Hartmut Lebmann, Guenther Roth (Hrsg.), Weber's Protestant Ethic: Origins, Evidence, Contexts (Publications of the German Historical Institute, Washington, D.C., Cambridge, New York 1993).

51 Ganz ähnlich Harold J. Berman, The Interaction of Spiritual and Secular Law: The Sixteenth-Century and Today (The Maurice and Muriel Fulton Lecture Series, Chicago 1997). 52 Albert A. Rabil, Jr. (Hrsg.), Renaissance Humanism: Foundations, Forms, and Legacy, 3 Bde. (Philadelphia 1988); Charles G. Nauert, Jr., Humanism and the Culture of Renaissance Europe (New Approaches to European History 6, hrsg. v. William Beik, T. C. W. Blanning, R. W. Scribner, Cambridge 1995); Peter Burke, The European Renaissance: Centres and Peripheries (The Making of Europe, Oxford, Malden, Mass. 1998). 
Wesensmerkmale des jeweiligen Volkskörpers. Aber sie sind auch keine bloßen Hirngespinste. Sie reflektieren die unterschiedliche Geschwindigkeit und die unterschiedliche Intensität, mit denen die Führung der römischen Kirche sich zunächst über Europa ausbreitete und dann von Laienhänden übernommen wurde. Nation ist ein relativer Begriff. Ihre Grenze liegt dort, wo der Vergleich mit den Nachbarn anfängt.

Dieser These steht natürlich eine grundlegende Tatsache entgegen, nämlich das Selbstverständnis der Reformatoren und ihrer Gegner selber. Aus der Warte eines Luther, eines Calvin, eines Zwingli, oder selbst eines Heinrich VIII. kann die Reformation kaum als Fortsetzung der Bemühungen der katholischen Kirche erklärt werden und aus der Perspektive eines Ignatius von Loyola oder Papst Paul IV erst recht nicht. Egal wie ausführlich die Gemeinsamkeiten zwischen ihnen auch nachgewiesen werden können ${ }^{53}$, und egal wie energisch die Reformatoren den von der Kirche längst in die Wege geleiteten Prozeß in Wirklichkeit beschleunigten, sie selber hatten keinen $Z$ weifel daran, daß sie mit der Tradition gebrochen (oder, umgekehrt, sie zum ersten Mal seit Jahrhunderten wieder wahrhaft hergestellt) und deshalb ganz Europa bitter gespalten hatten. Und gerade in Deutschland - von Hutten und Luther bis zu Hegel und Ranke - ging der Bruch mit der Tradition ganz eng mit einer neuen Wertschätzung des eigenen und Ablehnung des fremden nationalen Charakters Hand in Hand ${ }^{54}$.

Dieses konfessionelle und nationale Selbstverständnis der Akteure ist ein entscheidender Bestandteil der Reformation. Es darf aber nicht unkritisch hingenommen werden. Denn es ist nichts weiter, als die notwendige Voraussetzung für das gute Gewissen, ohne welches die Teilnehmer nie und nimmer in der Lage gewesen wären, sich gegen die heilige Macht der Kirche aufzulehnen, um sie in ihre eigenen Hände zu nehmen. Dieses gute Gewissen war um so notwendiger, je weniger Erfahrung man bisher mit der Kirche und ihren Methoden gemacht hatte, wie eben besonders in Deutschland, wo man sie bis vor kurzem gewissermaßen nur aus der Ferne hatte betrachten können. Machiavelli und Guicciardini lebten nah der Metropole. Sie waren mit den Methoden der Kirche schon lange so gut vertraut, daß sie es gar nicht nötig hatten, offiziell mit ihr zu brechen. Und da sie nicht offiziell mit der Kirche brechen mußten, konnten sie auch auf das gute Gewissen verzichten, das den Aufstand legitimierte. Aber in Wittenberg war die Kirche noch so heilig, daß sie ohne eine ebenso heilige Antitheologie nicht hätte angerührt werden können.

So läßt sich zum Schluß eine Antwort auf die eingangs gestellte Frage geben, woher die Reformation die unheimliche Kraft nimmt, ihre Einzigartigkeit allen

53 Z.B. bei Heinz Schilling, Luther, Loyola, Calvin und die europäische Neuzeit, in: Archiv für Reformationsgeschichte 85 (1994) 5-31.

54 Zum Zusammenhang von Reformation und Nationalismus im allgemeinen Benedict Anderson, Imagined Communities: Reflections on the Origin and Spread of Nationalism (London, New York 21991). Vgl. Orest Ranum (Hrsg.), National Consciousness, History, and Political Culture in Early-Modern Europe (Baltimore 1975); Ludwig Schmugge, Über ,nationale` Vorurteile im Mittelalter, in: Deutsches Archiv 38 (1982) 439-459. 
neueren und älteren Einsichten zum Trotz immer noch zu behaupten. Sie nimmt diese $\mathrm{Kraft}$ von den Historikern selber. Denn diese identifizieren sich immer noch in einem Maße mit dem Selbstverständnis von frühneuzeitlichen Reformatoren und Gegenreformatoren, Deutschen und Italienern, Franzosen und Engländern, Humanisten und Theologen, das ihnen selbst oft gar nicht bewußt ist und deshalb ihren Blick auf die Gemeinsamkeiten der ganzen europäischen Geschichte um so gründlicher verstellt ${ }^{55}$. Ihnen das übelzunehmen wäre ungerecht. Historiker sind die Erben eben jener frühneuzeitlichen Humanisten und Reformatoren, die einen so entscheidenden Beitrag zu der Entwicklung eines neuen europäischen Selbstverständnisses leisteten. Kein Wunder, daß sie sich mit dem Gegenstand identifizieren, dem sie ihre Existenz verdanken. Kein Wunder, daß sie allen Anstrengungen zum Trotz und oft zu ihrer eigenen Überraschung immer wieder bei einem Verständnis der frühen Neuzeit ankommen, das ausgerechnet die nationalen und konfessionalen Grenzziehungen bekräftigt, deren historische Entstehung sie eigentlich erklären wollen ${ }^{56}$.

Das bestätigt sich nicht zuletzt in der Verbindung von Reformations- mit Gesellschaftsgeschichte, die in den letzten Jahrzehnten die Bedeutung theologischer und nationaler Kriterien so erfolgreich in Frage gestellt hat ${ }^{57}$. Denn warum ausgerechnet die Gesellschaftsgeschichte sich damit einverstanden erklären sollte, ihrem Gegenstand Grenzen zu setzen, die von frühneuzeitlichen Theologen und Humanisten diktiert worden sind, ist schlechterdings nicht einzusehen. Die deutsche Reformation ist und bleibt ein theologisch und national definierter Begriff. Er läßt sich nicht gesellschaftsgeschichtlich verstehen. Das Verhältnis muß umgekehrt werden: Nicht die Geschichte der Reformation ist zu schreiben (um sie gegebenenfalls durch Analyse der Gesellschaft zu vertiefen) und schon gar nicht die Geschichte der Reformation im Kontext der Nation, sondern die Geschichte der europäischen Gesellschaft (um sie gegebenenfalls in theologischer und nationaler Hinsicht zu vertiefen). Denn die Gesellschaft - die Menschen und ihre sich stetig wandelnden Beziehungen zueinander - ist der eigentliche Gegenstand historischer Betrachtung ${ }^{58}$. Die deutsche Reformation ist nur die Form, in der sich dieser

55 Klassische Ausnahmen, bezeichnenderweise aus der Geschichte der Literatur, sind Ernst Robert Curtius, Europäische Literatur und lateinisches Mittelalter (Bern 21954) und Erich Auerbach, Mimesis: Dargestellte Wirklichkeit in der abendländischen Literatur (Bern 21959) - geradezu Zwillingsbücher.

${ }^{56}$ Robert W. Scribner, Roy Porter, Mikulás Teich (Hrsg.), The Reformation in National Context (Cambridge, New York 1994).

57 Gut zu belegen in den Unterschieden zwischen Geoffrey R. Elton (Hrsg.), The Reformation, 1520-1559 (New Cambridge Modern History, Bd. 2, Cambridge 1958) und der zweiten Auflage desselben Bandes von 1990; vgl. Euan Cameron, The European Reformation (Oxford 1991); Robert W. Scribner, Is There a Social History of the Reformation?, in: Social History 4 (1977) 483-505 und Thomas A. Brady, Jr., Social History, in: Steven E. Ozment (Hrsg.), Reformation Europe: A Guide to Research (St. Louis 1982) 161-81.

58 Wie Norbert Elias in der Einleitung zur Neuauflage von Über den Prozeß der Zivilisation: Soziogenetische und psychogenetische Untersuchungen, 2 Bde. (Bern, München ${ }^{2} 1969$ ) besonders klar und nachdrücklich formuliert hat. 
Gegenstand zu einer bestimmten Gelegenheit in einer bestimmten Gegend Europas ausgeprägt hat.

Luther wird manchmal mit Papst Gregor VII. verglichen. Dieser Vergleich muß ernst genommen werden, denn die Reformation war unter anderem auch ein Investiturstreit. Ganz wie zu Zeiten Gregors VII. ging es darum, die Grenze zwischen Himmel und Erde neu zu bestimmen. Daß diese Grenze im 11. Jahrhundert durch die Besetzung von geistlichen Herrschaften, im 16. aber durch die päpstliche Finanzwirtschaft besonders eindrücklich bedroht wurde, ist ein historischer Unterschied, der an der Identität der zugrundeliegenden Problematik nur wenig ändert. Das wird aber erst dann zu erkennen sein, wenn Reformationshistoriker von konfessionellen und nationalen Kategorien soweit Abstand nehmen werden, daß sie dieselben in ihren Untersuchungen der Reformation nicht mehr stillschweigend voraussetzen, sondern sich entweder ganz bewußt zu ihnen bekennen, oder sie als die versteinerten Überreste der Vergleiche behandeln, die Europäer der frühen Neuzeit unter sich und mit ihren Vorfahren anzustellen pflegten. 